\title{
Using Simulated Instruction to Prepare Students to Engage in Culturally Competent Practice
}

\author{
Alex D. Colvin, PhD \\ Texas Woman's University, Denton, Texas, United States \\ (iD) https://orcid.org/0000-0002-0480-9195 \\ Mahasin Saleh, PhD \\ Doha Institute for Graduate Studies, Doha, Qatar \\ Nila Ricks, $\mathrm{PhD}$ \\ Texas Woman's University, Denton, Texas, United States \\ Emarely Rosa-Davila, $\mathrm{PhD}$ \\ Texas Woman's University, Denton, Texas, United States
}

Contact: acolvin3@twu.edu

\begin{abstract}
Developing and training students to understand issues of diversity, including the development of a culturally competent social work identity, has long been a challenge for schools of social work. Nevertheless, preparing students to engage with diverse populations is paramount. Simulated learning is an effective pedagogy to enhance and broaden students' understanding in regard to engaging with diverse populations. This article examines the use of human simulation instruction activities to prepare students to engage in culturally competent practice. More specifically, in this article, the constructs of the cultural competence practice model of Campinha-Bacote (2002) will be examined for practical application in social work education.
\end{abstract}

Keywords: Council on Social Work Education (CSWE) accreditation, diversity, cultural awareness, cultural competence, human simulation, social work education

Date Submitted: November 12, 2019 | Date Published: January 28, 2020

\section{Recommended Citation}

Colvin, A. D., Saleh, M., Ricks, N., \& Rosa-Davila, E. (2020). Using simulated instruction to prepare students to engage in culturally competent practice. Journal of Social Work in the Global Community, 5, 1-18.

https://doi.org/10.5590/JSWGC.2020.05.1.01 


\section{Introduction}

The United States continues to undergo major demographic changes, increasing the diversity of the population (National Association of Social Workers [NASW], 2015). According to Pew Research Center (2015), the country's racial profile will be vastly different by 2055. Growth in the Hispanic, Black, and Asian and Pacific Islander populations in the United States is predicted to almost triple over the next 40 years (World Population Review, 2019). It is forecast that, by 2055, 51\% of the U.S. population will be composed of Hispanics, Asians, and African Americans (World Population Review, 2019). As the U.S. population continues to become more diverse, the ability to understand and work effectively with individuals from various races, cultures, religious, and ethnic backgrounds will be of increasing importance in social work practice (Vesely et al., 2014).

With social workers playing a key role in providing human service delivery to diverse populations (T. S. Davis, 2009), it is important for social work educators to equip students with the competence and skills necessary to provide culturally responsive practice with these populations. According to Zubrzycki et al. (2014), culturally responsive practice refers to the development of "collaborative and respectful relationships with culturally, racially, and ethnically diverse populations in order to respond to the issues and needs of groups in ways that promote social justice and uphold human rights" (p. 21). The journey toward cultural responsiveness necessitates awareness and understanding of diverse populations' ways of knowing, being, and doing. For this reason, a major responsibility of schools of social work is to prepare students to facilitate and promote social justice and to be culturally responsive in their future practice (Bender et al, 2010). This must include fostering students' self-awareness and respect for diverse groups as well as helping them to develop a culturally responsive identity.

The Council on Social Work Education's (CSWE) Educational Policy and Accreditation Standards (EPAS) mandates that social work graduates understand how diversity and difference characterize and shape the human experience. This includes an understanding of the forms and mechanisms of oppression and discrimination (CSWE, 2015). To this end, student awareness of diversity needs to be enhanced, not only through course lectures and information dissemination but also through the use of practice opportunities that can be monitored, measured, and critiqued.

Social work education has a long history of using peer to peer roleplays as an experiential teaching approach to aid students in sharpening their client engagement, interviewing, and assessment skills (Bogo et al., 2014). Role plays provide opportunities for students to build interaction skills in social work classrooms, while also helping students achieve a sense of self-awareness (Gardner, 2001) and self-efficacy (Petrovich, 2004) and instructing students on interaction skills (Reid \& Hanrahan, 1982). Role plays have been found to be valuable tools to assess whether students are ready for practice (Duffy et al., 2013), to develop group work skills (Macgowan \& Vakharia, 2012), and to promote reflective learning, particularly when coupled with videotaped analysis (Bolger, 2014; Dempsey et al., 2001). Participating in roleplays allows students to examine their own family of origin, personal experiences, biases, and beliefs about specific populations, and may lead to greater appreciation of transference and countertransference issues (Friedman \& Goldbaum, 2016). Through the roleplay experience, students have the opportunity to discuss controversial or complex topics, which can help reduce defensiveness once students enter the workforce (Villadsen et al., 2012).

Simulation is a core pedagogy for many disciplines, such as the healthcare professions, aviation, law, and military, and has been used for over 20 years (Gaba, 2007). More recently, human simulation has attracted increased attention in social work education as an effective pedagogical approach to teaching practice. Simulation is described as "a pedagogy using a real world problem in a realistic environment to promote critical thinking, problem solving, and learning" (Nimmagadda \& Murphy, 2014, p. 540). The term human 
simulation refers broadly to activities in which students interact with trained actors as simulated clients in a real-world practice setting or practice laboratory that closely resembles a real work practice setting. Actors can include theater students or professionals who have practiced in the field of social work over a number of years. Human simulation is designed to provide opportunities for learners of all levels to practice and demonstrate a set of skills or to become adept at dealing with situations that will likely occur in the future (Fowler \& Pusch, 2010).

Research in other disciplines has demonstrated that simulations raise student self-awareness, which can be used in refining professional skills (Bolesta \& Chmil, 2014; Potter \& Allen, 2013). Simulation studies involving social work have focused on interprofessional education and the healthcare context (Nimmagadda \& Murphy, 2014; Olson et al., 2015; Thompson et al., 2016). Studies by Bogo et al. (2014), B. Johnson and Rawlings (2011), and $\mathrm{Lu}$ et al. (2011) have demonstrated that human simulation in social work can be used successfully to teach or to assess competence in an integrated manner in graduate and undergraduate foundation practice, and in specialized areas such as clinical competence and cultural sensitivity. Social work simulations also enable students to learn how to integrate social work theory, knowledge, skills, and values into practice. Use of this pedagogy provides students with opportunities to practice clinical skills and to actively engage in reflective practice activities so students feel more confident and competent as they begin to provide services to clients (Sunarich \& Rowan, 2017).

While social work education has used roleplaying and case studies for many years, human simulation moves beyond roleplays as traditional educational techniques in several ways. First, simulations do not take place in the classroom, but in settings that represent real life, such as a clinic or emergency department or specifically designed practice laboratories that closely resemble clinical practice settings (Hitchcock, 2017). Role plays on the other hand often occur in classroom settings. Secondly, participants in human simulations are trained as actors and asked to act in specific roles. Students assume their future professional role and treat the simulated experience as a real-world situation (Hitchcock, 2017).

During simulation, students focus less on the acting skills of the simulated client and more on building their own skills (Petracchi \& Collins, 2006). In roleplays, in contrast, peers may portray challenging clients (Miller, 2004). For that reason, the roleplay situation may not feel authentic enough for students to engage, and the roleplay may initially feel stilted or unnatural (Lane \& Rollnick, 2007). For example, because of a potential lack of structure over how the roleplay may unfold and what it should entail (Petracchi \& Collins, 2006), students may find it easy to try to pretend or fake using a skill when working with peers (Rogers \& Welch, 2009). Thirdly, during human simulations, when interviewing simulated clients, students are provided with feedback from multiple sources at various points as well as opportunities for repeated performance to refine competency-based skills (Ericsson, 2008; Mooradian, 2008). For example, following the simulation, students are provided comprehensive and descriptive feedback on performance. This might include reviewing one's own practice via video or audio recording. Additionally, descriptive feedback is provided by the educator who observed the student and provided guidance, highlighting the individual's strengths and weaknesses in a supportive manner (Lane \& Rollnick, 2007). As a pedagogy, human simulations can be used in conjunction with structured reflection exercises to evaluate practice competencies (Bogo, Regehr, Katz, et al., 2011; Bogo, Regehr, Logie, et al., 2011; Bogo et al., 2013).

Finally, simulation includes a comprehensive debriefing between the participants (students or practitioners) focusing on the simulation's content. Following the simulation, the student meets with the instructor to discuss how the interview went, covering the areas of both competency and improvement (Hitchcock, 2017). In roleplaying, on the other hand, students and instructors can interrupt the roleplay experience (Moss, 2000). The key to the debriefing session is to create a safe space for the student, as the simulated experience may have been the first time a social work student had encountered a client situation (Hitchcock 2017). 
Conversely, students who already have substantial practice experience may feel they are being heavily criticized by peers and the instructor (Hargreaves \& Hadlow, 1997). Furthermore, students may be less willing to accept constructive feedback from peers (Rogers \& Welch, 2009), thus necessitating the need for guidelines on how to give and receive constructive feedback (Hargreaves \& Hadlow, 1997). Lastly, Mooradian (2008) noted that students reported that experience with simulation with a trained actor was more valuable than roleplay because of the authenticity of the experience.

The purpose of this article is to provide an examination of the use of human simulation instruction activities to prepare students to engage in future culturally competent practice. For this article, the cultural competence practice model of Campinha-Bacote (2002) will be analyzed for practical application to social work education. The Campinha-Bacote framework proposes five interdependent constructs (cultural awareness, cultural knowledge, cultural skill, cultural encounter, and cultural desire) that guide the process of developing culturally competent practitioners. These five constructs will be integrated into the discussion.

\section{Overview of Cultural Competence}

There have been various iterations of the notion of cultural competence over the years, as described by different authors, including ethnic competence (Gallegos, 1982; Green, 1995) and cultural awareness (Winkelman, 2005). Other culturally related terms have included cultural responsiveness, cultural proficiency, and cultural sensitivity. The majority of authors eventually converge on the term cultural competence (Cross et al., 1989; Lum, 2005; Weaver, 2005). The term cultural competence has become ubiquitous in human services language and settings (Gallegos et al., 2008). Gallegos (1982) provided one of the first conceptualizations of ethnic competence in the social work literature, describing it as

a set of procedures and activities to be used in acquiring culturally relevant insights into the problems of minority clients and the means of applying such insights to the development of intervention strategies that are culturally appropriate for these clients. (p. 4)

The term has also been used in counseling psychology literature (Pedersen \& Marsell, 1982; Sue et al., 1982; Vera \& Speight, 2003). By the early 2000s, a number of articles calling for cultural competence in nursing and education had been published, and similar articles have appeared in the medical education literature (Bigby, 2003; Suh, 2004). Cultural competence has even been included as an accreditation standard in medical education (Liaison Committee on Medical Education, 2012).

Cultural competence refers to the process by which individuals and systems respond respectfully and effectively to people of all cultures, languages, classes, races, ethnic backgrounds, religions, spiritual traditions, immigration status, and other diversity factors in a manner that recognizes, affirms, and values the worth of individuals, families, and communities and protects and preserves the dignity of each (Fong, 2004; Fong \& Furuto, 2001; Lum, 2011).

Cultural competence has at various times been defined in many ways. Operationally, cultural competence is the integration and transformation of knowledge about individuals and groups of people into specific standards, policies, practices, and attitudes used in appropriate cultural settings to enhance the quality of services, thereby producing better outcomes (P. Davis \& Donald, 1997). Cross (1988) defined cultural competence as "a set of congruent behaviors, attitudes, and policies that come together in a system, agency, or among professionals and enable that system, agency, or those professionals to work effectively in crosscultural situations" (p. 1). Similarly, McPhatter (1997) described cultural competence as the ability to 
transform knowledge and cultural awareness into health or psychosocial interventions that support and sustain healthy client-system functioning within the appropriate cultural context.

In social work practice, cultural competence implies a heightened consciousness of how culturally diverse populations experience their uniqueness and deal with their differences and similarities within a larger social context (NASW, 2017). Concurrently, cultural competence requires social workers to use an intersectionality approach to practice, examining forms of oppression, discrimination, and domination through diverse components of race and ethnicity, immigration and refugee status, religion and spirituality, sexual orientation and gender identity and expression, social class, and abilities. Further, cultural competence requires social workers to acknowledge their own position of power vis-à-vis the populations they serve and to practice cultural humility (Tervalon \& Murray-Garcia, 1998). Cultural humility involves working with clients on all levels, with a presence and awareness of the limitations of one's own cultural horizon of expectations while at the same time learning, communicating, offering help, and making decisions in professional practice and settings (NASW, 2015). According to Tervalon and Murray-Garcia (1998), cultural humility includes an enduring commitment to incorporating self-evaluation and self-critique, and redressing power imbalances while developing advocacy and clinical partnerships with communities on their behalf. These relations and actions are developed in a non-paternalistic and mutually beneficial manner. The achievement of cultural competence is an ongoing process that requires that the individual develop competence. According to the National Association of Social Workers (NASW) Code of Ethics (2017), to be culturally competent,

Social workers should obtain education about and seek to understand the nature of social diversity and oppression with respect to race, ethnicity, national origin, color, sex, sexual orientation, gender identity or expression, age, marital status, political belief, religion, immigration status, and mental or physical ability. (Ethical Standard 1.05c)

The CSWE (2015), which is the standard bearer for schools of social work accreditation, asserts that social work programs are expected to "prepare students to learn about differences, to value and respect diversity, and develop a commitment to cultural humility" (p. 7). The dimensions of diversity are understood as the intersectionality of multiple factors, including but not limited to age, class, culture, disability and ability, ethnicity, gender, gender identity and expression, immigration status, marital status, political ideology, race, religion/spirituality, sex, sexual orientation, and tribal sovereign status (p. 7). Therefore, the CSWE EPAS focuses on developing students' abilities to work with diverse groups (Congress et al., 2009; CSWE, 2008). The EPAS presents core competencies to guide students in attaining proficiency. According to the EPAS, competencies are measurable behaviors that consist of the enhancement of students' knowledge, values, skills, and cognitive and affective processes. The goal of these outcomes is to demonstrate the integration and application of the competencies in practice situations in a purposeful, intentional, and professional manner to promote human and community well-being (CSWE, 2015, p. 6).

Specifically, Competency 2 calls for students to understand how diversity and difference characterize and shape the human experience (CSWE, 2015). This includes the precept that students need to comprehend the scope of various cultural structures that can oppress and reinforce power and privilege. In addition, students must manage personal biases by applying self-regulation and self-awareness in working with diverse populations. Throughout this process students must also communicate and apply a clear understanding of the critical nature of diversity and difference in the shaping of human experience. Finally, students must identify as learners, and engage and work with clients by acknowledging them as "experts of their own experience" (p. 7). According to EPAS, such activities are critical to the formation of students' future identities (CSWE, 2015). 


\section{Theoretical Framework}

\section{Campinha-Bacote Culturally Competent Practice Model}

The Campinha-Bacote process of cultural competent healthcare framework encompasses five constructs: cultural awareness, cultural knowledge, cultural skill, cultural encounter, and cultural desire. Using these components, the Campinha-Bacote (2002) model emphasizes that the acquisition of cultural competence is "a process not an end point" (p. 181). Thus, it is proposed that cultural competence knowledge-building on the part of the student be approached as an ongoing and instructive process, whereby learning encompasses continual evolution rather than it being approached with the notion of the achievement of cultural competence as the goal (Campinha-Bacote, 2002). Because the profession of social work requires practitioners to acquire a heightened consciousness of the client's uniqueness, particularly within their cultural context, integrating the tenets of Campinha-Bacote can serve as a linkage to the competencies already present within social work education and training. Specifically, the framework can be a means to teach social work students not only to gain increased knowledge of diverse cultures but also a means to assess practice and learning skills, using action-oriented steps within practice. In this section, each of the five model constructs (cultural awareness, cultural knowledge, cultural skill, cultural encounter, and cultural desire) is discussed. In addition, the constructs of the Campinha-Bacote culturally competent practice model are connected with specific opportunities for students to become culturally competent through the integration of simulations, as evidenced in the social work literature.

\section{Cultural Awareness}

Campinha-Bacote's (2002) construct of cultural awareness posits that, to move toward culturally competent practice, it is imperative to engage in self-awareness and an in-depth exploration of one's personal biases, stereotypes, prejudices, and assumptions that are held about individuals who are different from oneself. This exploratory process should occur in a conscious, deliberate, and reflective manner (Campinha-Bacote, 2002). The importance of this construct lies in increasing students' awareness and reducing the risk of them imposing their own cultural values onto the client during encounters. This aligns with Competency 2 of the EPAS, "Engage Diversity and Difference in Practice," which calls for self-awareness and self-regulation to manage the influences of personal biases and values when working with diverse clients and constituencies (CSWE, 2015, p. 7). With a focus on this construct, the goal of simulation activities is to develop an awareness that cultural beliefs and values influence conscious and unconscious thoughts and to understand that these create bias in regard to acceptable behavior (Bauer \& Bai, 2018). Therefore, in an effort to augment student knowledge to arrive at appropriate culturally competent practice behaviors, simulation activities can be employed to guide students in examining their ethnocentric positions, learned convictions, and longheld stereotypes (Campinha-Bacote, 1998).

Because the profession of social work requires maintaining an awareness of personal values, beliefs, and biases, simulation activities can be a catalyst for gaining insight into one's identity and how it positions oneself in society. This insight involves areas of self that include race, ethnicity, gender identity, sexual orientation, physical abilities, socioeconomic status, and cultural background, among others (Bender et al., 2010). Given that most social work students will be working directly with clients, self-awareness should be emphasized in social work education. Although a considerable body of research indicates a strong relationship between increased self-awareness and cultural competency among counselors as a specified group of helping professionals (Richardson \& Molinaro, 1996; Sue, 2001), less is known about how to foster social work students' self-awareness to develop culturally responsive future social work practitioners (Bender et al., 2010). Therefore, exercises that involve self-discovery and self-awareness can serve as a means to address these issues (Cramer et al., 2012). 
To create student populations that are more culturally aware, social work educators can integrate crosscultural human simulation activities into the curriculum. In a study by Petracchi and Collins (2006), simulation exercises were integrated into the curriculum, which introduced students to the methods of social work practice. Specifically, the activities were used to teach students how to develop knowledge, values, and skills in the utilization of effective techniques of worker-client communication; structuring helping interviews; and establishing, maintaining, and terminating working relationships with client systems of various ethnographic backgrounds. Using human simulation activities further allows students to reflect on their own experiences and awareness of discrimination and how these experiences influenced their identity (Bender et al., 2010). In a study by Mooradian (2007), students reported that human simulations helped them to think about things that they would do differently.

\section{Cultural Knowledge}

Campinha-Bacote's (2002) construct of cultural knowledge calls for professionals to seek a sound educational foundation in regard to diverse groups, including an exploration of demographic, epidemiological, and socioeconomic data to achieve an in-depth understanding and acceptance of meaning variations across different cultural, racial, and ethnic groups. This construct aligns with Competency 2 of the EPAS, which instructs social workers to present themselves as learners and engage clients and constituents as experts of their own experience (CSWE, 2015, p. 7).

Cultural knowledge-building should encompass student understanding of the interconnections among the socioeconomic and sociocultural realities faced by many clients, such as how exposure to poverty, crime, substandard housing and neighborhood conditions, lack of adequate insurance, insufficient access to quality health care, violence, racism, and discrimination are linked to poor health and mental health outcomes (Chadiha \& Brown, 2002; Klonoff et al., 1999; Leventhal \& Brooks-Gunn, 2003; Mechanic, 2005; Satcher et al., 2005; Williams \& Jackson, 2005). Further, cultural knowledge-building should include the student's recognition of the minority client's potential areas of dissonance that may affect how that client responds to service delivery systems. These areas of dissonance may include such concerns as the client's lack of trust of the service provider, apprehension about the service provider's motives, lack of self-disclosure of needed information, and passive or avoidant behaviors. In an effort to strengthen students' cultural knowledgebuilding, simulation activities can be employed to assist social work students in exploring the sociocultural realities faced by culturally, racially, or ethnically diverse client groups.

Active forms of learning through simulation activities also provide opportunities for students to deepen their knowledge for working with various cultural groups and to develop appropriate practice skills as well as to prepare them for future cultural encounters (Cramer et al., 2012). For example, specific cultural-based intervention exercises can be integrated as a human simulation activity to enhance students' cultural knowledge. These cultural-based interventions can include interactive drama that focuses on the issues of racism, sexism, heterosexism, and classism.

Wilson et al. (2013) used human simulations to evaluate students' direct practice skills in preparation for home visits with clients. Simulations related to home visits are beneficial to students because they can help students learn appropriate ways to respond when visiting the homes of clients from different cultures. For example, the client may offer food, prayer, gifts, or related items, often associated with the client's culture, and simulations can prepare students to respond appropriately to such offers. Simulation technology can also be used to help students learn techniques to adequately serve clients who experience poverty, racism, discrimination, oppression, or microaggressions. For example, a trained actor can represent an oppressed, minority client, living in an impoverished neighborhood, who experienced discrimination when applying for employment. Students can practice appropriate ways to respond and help the client navigate their challenges. 
It is imperative that students learn appropriate ways to respond in these situations so that they do not offend their client or harm the helping relationship between the social worker and the client.

Through the use of experimental exercises, students are able to critically examine their own conscious or unconscious ways of being and challenge their longheld values and ways of everyday thinking that have been shaped by societal norms. In addition, these exercises help the student to engage in the overarching themes of the social work profession: social and economic justice (Cramer et. al., 2012). Such exercises also help students to become more sensitized to the needs and experiences of diverse client populations (Cramer et. al., 2012).

\section{Cultural Encounters}

Cultural encounters, according to Campinha-Bacote (2002), are processes that encourage individuals to engage in direct, face-to-face, cross-cultural interactions with clients. These encounters allow individuals to better educate themselves regarding the clients' experiences and work to refine or modify their existing beliefs or stereotypes about groups served (Campinha-Bacote, 2002). Such encounters with individuals from diverse cultural backgrounds also help to build an appreciation of alternative interpretations of reality and enable the social worker to question preexisting beliefs about a specific cultural group. Accordingly, these encounters become the pivotal construct that provides individuals with opportunities to develop the foundation for their journey toward cultural competence.

Given the importance of these encounters, it must be understood that it is not sufficient merely to say that one respects a client's values, beliefs, and practices or to go through the motions of providing a culturally specific intervention (Campinha-Bacote, 2002). For that reason, EPAS Educational Policy 3.o, "Advance Human Rights and Social, Economic, and Environmental Justice," suggests that social work programs provide expectations for and the context in which students learn about differences, as well as to value and respect diversity and develop a commitment to cultural humility (CSWE, 2015, p. 14). Although there may be occasions when previous interactions with three or four people from one particular cultural, racial, or ethnic group provides a sufficient knowledge base about the group, it must not be assumed that such few interactions makes one an expert on the group (Campinha-Bacote, 2002); it may require a number of encounters over a period of time with a given cultural, racial, or ethnic group to begin to become securely acquainted with the practices of that group. Human simulations provide social work students with an opportunity to practice their knowledge-building related to encounters and engagements with diverse client groups as well as addressing and assessing their own issues of race, bias, and racism (Logie et al., 2013).

Helping students' foster better understanding of and communication with individuals who are different from themselves is key. As such, integrating human simulations that involve cross-cultural interactions will help students to gain skills and understand how cultural values influence the way other groups are viewed. Overall, human simulated activities help to prepare students for future cultural encounters.

\section{Cultural Skill}

Cultural skill is the ability to use appropriate cross-cultural communication skills to collect relevant cultural data to provide an appropriate and sensitive client-centered intervention. This includes learning about how physical, biological, and physiological variations influence one's ability to conduct an accurate and appropriate physical examination (Campinha-Bacote, 2002). In terms of social work, it means developing the skills to conduct a culturally competent biopsychosocial assessment to gather all possible data regarding the client's present situation. The goal is to explore the client's explanation of his or her or their presenting problem (Campinha-Bacote, 2009). To develop cultural skills, social work students need to understand the 
forms and mechanisms of oppression and discrimination, and to recognize the extent to which a culture's structures and values, including social, economic, political, and cultural exclusions, may oppress, marginalize, or alienate, or create privilege and power (CSWE, 2015, p.7).

Human simulations provide students with opportunities to build and improve core practice skills where trained actors portray culturally, racially, or ethnically diverse clients. This includes building skills in crosscultural engagement, reflective listening, validation of feelings, and so forth (LeGeros \& Borne, 2012). For example, a simulation might include a volunteer from a difference cultural group who acts as a client and struggling with expressing their feelings of depression while the social work student conducts an initial assessment interview and intervention (Hitchcock, 2017).

Cultural skills can further be fostered by engaging students in activities that will broaden their understanding about how to interact with groups different than themselves. This engagement can include the use of intercultural simulation activities. Intercultural simulation activities are instructional activities that engage and challenge participants with certain experiences integral to encounters between people of more than one cultural group. The cultures can be national, ethnic, occupational, gender, racial, or any other groups that can be construed as a culture due to inherent differences in values, norms, behavior patterns, and the like (Fowler \& Pusch, 2010). Intercultural human simulation activities are designed and conducted to develop skills and prepare participants for future experiences in a different or unknown cultural environment. Thus, there is an emphasis on the general characteristics of culture, the process of interacting with those who are culturally different, and the values and beliefs that may affect behavior (Fowler \& Pusch, 2010). In their study, Petracchi and Collins (2006) found that students remarked that human simulation activities gave them a "real" opportunity to show their skills. Students reported, "it was one thing to read and talk about our skills, but to actually put them into practice so we can critique them is the ultimate learning experience" (Petracchi \& Collins, 2006, p. 229).

Human simulations also can be used to prepare students to work in specific social work settings where they will encounter cultural challenges. For example, Sunarich and Rowan (2017) used human simulations to evaluate diversity skill development for social work field students placed in pediatric hospitals. Simulation scenarios specific to medical settings can focus on the role that culture plays in end-of-life care and client decision making. They also can focus on integrating clients' cultural beliefs and practices into treatment for specific medical conditions.

\section{Cultural Desire}

Campinha-Bacote (2002) asserted that the individual should possess a cultural desire to know more about cultural, racial, and ethnic groups. Cultural desire, seen as the most critical construct in the process of developing cultural competence, involves an intrinsic motivation or genuine passion to be open and flexible with others, accept differences, build similarities, and be willing to learn from others as cultural informants. Accordingly, Campinha-Bacote (2002) suggested that cultural desire requires individuals to be self-motivated to acquire cultural competence, rather than having to be coerced to do so through regulatory mechanisms. By valuing diversity, students are more likely to provide appropriate and compassionate service and meet the needs of their clients (Bauer \& Bai, 2018).

Campinha-Bacote (2002) also suggested that humility is a key factor in addressing one's cultural desire and defined cultural humility as the quality of seeing greatness in others and coming to the realization of the dignity and worth of others (Campinha-Bacote, 2009). Because this construct serves as the most critical guidepost in the process of developing cultural proficiency, the social work field educator's role becomes paramount. As educators, it is important to teach future social workers that cultural desire is expressed in 
terms of human dignity, human rights, social justice, and equity (Campinha-Bacote, 2009) and that this is part of social workers' ethics code. Simulation can serve as an important training mechanism to aid students to become self-motivated to want to acquire more knowledge of experiences of diverse client groups.

Student exposure to diversity activities increases their cultural desire and their willingness to work with diverse populations, thus increasing their cultural competence (Hawala-Druy \& Hill, 2012; Hayward \& Li, 2014). Simulations can serve as a diversity activity to promote culture desire. For example, simulations to address the cultural desire construct can focus on specific ways that clients are discriminated against or oppressed. Students can practice appropriate ways to respond to and empower their clients. In addition, the scenarios can lead to discussions about specific steps that students can take to advocate for their clients, and concrete strategies to promote equality, humility, and social and economic justice. Simulation scenarios can also focus on helping clients to process an array of emotions associated with racism, sexism, classism, and other forms of discrimination and oppression. Another means to address the cultural desire construct is to engage students in reflective thinking and discussions regarding their experience with simulations that address the various facets of diversity. More specifically, they could discuss how the simulations have motivated a desire to become more culturally competent outside of the classroom, including awareness in areas where they need continued growth and development. In the next section, we will provide recommendations for social work education.

\section{Recommendations for Social Work Education}

When considering the use of experiential exercises, specifically, the integration of human simulations to create and enhance students' cultural competence, social work instructors must weigh the potential positive and negative consequences of such exercises. More importantly, instructors should be very deliberate in their decision making about whether to use such exercises, how to present the exercise, and the plan for processing the activities (Cramer et al., 2012). Specifically, educators should consider the timing of the class context, learning needs, students' personal experiences, and the maturity of the students, including their readiness to engage in such simulated activities (Latting, 1990). When engaging in cultural simulation activities, instructors must remember to provide qualitative feedback as well as to leave sufficient time for debriefing of the learning activity (Nagda et al., 1999). Additional recommendations for social work educators to take into account when considering or using human simulation activities are as follows:

- Introduce human simulation activities to students early in the program to ensure that they are prepared for their field placements and to interact with diverse clients.

- Focus on the students' performance in the simulation, that is, how well they performed and how they applied their skills, including in relation to cultural competency.

- Ensure that the simulations address the multiple aspects and complexities of diversity that lead to cultural competency (Boet et al., 2014).

- Use formal or informal evaluation of simulation education activities to provide evidence of effectiveness and to build on the pedagogical research base. The results can also provide additional information that can be used to improve teaching cultural competence.

- Actively involve students in the pre- and postevaluation of simulation activities so that students can gain insight into their own growth and room for development on the path to cultural competency (Boet et al., 2014). 
- Include multiple levels of student participation in simulations, such that new students can learn from students who are further along in the program (Boet et al., 2014).

- $\quad$ Provide a safe space time for debriefing and feedback, as students will need opportunities to ask questions and process their emotions.

- Continue to expand faculty cultural competence skills through continuing education, workshops, presentations, and related activities (Saleh et al., 2011).

- Ensure that faculty have a sincere willingness to explore new teaching approaches, such as simulations, to specifically promote cultural competence.

- Provide opportunities for interprofessional simulation education in relation to cultural competence (Boet et al., 2014). Interprofessional education can benefit all students in simulating real-world settings and provide economic savings to universities through the use of shared resources.

Although implementing simulation activities can provide many benefits, there are also potential limitations. The documented barriers to using simulation include the investment of cost and time (and competition for these from other components of a curriculum), the need for support from senior administration, and scheduling or time allotment (Motola et al., 2013). For some, a potential drawback of using human simulation is the expense. Prices may vary, but researchers have noted that paying for experienced, reliable actors for a training workshop can be costly. In their study, Kurtz and colleagues (2017) reported that employing reliable trained actors cost around $\$ 200$ per day per actor. Also, Hanberg (2008), in his study of 323 faculty members, reported that one of the major barriers to integrating simulation was lack of funding. It was also noted that faculty felt a higher degree of administrative input into the planning was needed when adding simulation into the curriculum (Hanberg, 2008). Along with this, other limitations included time and faculty training. In a study by Jones and Hegge (2008), faculty reported that at least 0.50 full-time employee was needed to plan the use of simulation in their courses. In the same study, it was reported by $44.8 \%$ of faculty that 0.50 fulltime employee was necessary to implement simulation in their courses. The time-consuming nature of the training and selection of actors, and the organization process were seen as other potential challenges (Kurtz et al., 2017).

For some educators, the cost of simulation education may be prohibitive. Even if cost is not a barrier, we recommended that social work educators explore and pursue interdisciplinary simulation education partnerships with nursing and medical schools and other helping profession disciplines that may already have simulation facilities and infrastructure. An interdisciplinary training model can benefit all students involved, because it provides the opportunity to experience the real world of practice by working in a team with diverse clients. These simulation experiences will help students move forward on their future path as professionals experiencing and envisioning cultural competence and the promotion of social justice.

\section{Conclusion}

Cultural competence is an essential educational goal for social work students. Social workers have an ethical obligation to be culturally competent, which accentuates the importance of preparing competent practitioners. As social workers are called to recognize and change human interactions and relationships in an effort to transform cultural and social institutions, it becomes extremely important for social work educators to be intentional about preparing students for practice with diverse clients. For this reason, human simulation activities can be used as a tool to challenge students' understanding and future engagement in social change. This includes using human simulations exercises in ways that not only optimize practice skills with diverse 
populations but also aid students in examining how they can understand and embrace difference, challenge social, political, and economic conditions, and work to create meaningful change in an effort to improve human and social conditions (C. H. Johnson et al., 2001).

The purpose of this article was to provide an examination of the use of human simulations as a teaching technique to prepare social work students for culturally competent practice. Human simulations also provide students with innovative opportunities to practice scenarios in a safe, supervised setting that they may encounter in the field. The five constructs from Campinha-Bacote's (2002) culturally competent practice framework were presented and applied to specific opportunities for students to become culturally competent through integration of simulations. We also provided recommendations for social work educators to consider when integrating simulations. Overall, research demonstrates that, through human simulations, students report improvement in their skills, insight into their abilities, and the ability to discuss fears and concerns that they have with a particular situation. In addition, instructors report significant improvement in students' interview skills. Although human simulation activities are not new to social work education, the research is scant in regard to their use in promoting cultural competence. Thus, additional research that includes rigorous evaluation is needed to determine the impact of simulation education on social work practice skills.

\section{References}

Bauer, K., \& Bai, Y. (2018). Using a model to design activity-based educational experiences to improve cultural competency among graduate students. Pharmacy, 6(48), 2-11. https://doi.org/10.3390/pharmacy6020048

Bender, K., Negi, N., \& Fowler, D. N. (2010). Exploring the relationship between self-awareness and student commitment and understanding of culturally responsive social work practice. Journal of Ethnic \& Cultural Diversity in Social Work, 19(1), 34-53. https://doi.org/10.1080/15313200903531990

Bigby, J. (2003). Cross-cultural medicine. American College of Physicians.

Boet, S., Bould, D., Burn, C. L., \& Reeves, S. (2014). Twelve tips for a successful interprofessional team-based high fidelity simulation education session. Medical Teacher, 36, 853-857. https://doi.org/10.3109/0142159X.2014.923558

Bogo, M., Katz, E., Regehr, C., Logie, C., Mylopoulos, M., \& Tufford, L. (2013). Toward understanding metacompetence: An analysis of students' reflection on their simulated interviews. Social Work Education, 32(2), 259-273. https://doi.org/10.1080/02615479.2012.738662

Bogo, M., Rawlings, M., Katz, E., \& Logie, C. (2014). Using simulation in assessment and teaching: OSCE adapted for social work. Council on Social Work Education.

Bogo, M., Regehr, C., Katz, E., Logie, C., Mylopoulos, M., \& Regehr, G. (2011). Developing a tool to assess student reflections. Social Work Education, 30(2), 186-195. https://doi.org/10.1080/02615479.2011.540392

Bogo, M., Regehr, C., Logie, C., Katz, E., Mylopoulos, M., \& Regehr, G. (2011). Adapting objective structured clinical examinations to assess social work students' performance and reflections. Journal of Social Work Education, 47(1), 5-18. . https://doi.org/10.5175/JSWE.2011.200900036

Bolesta, S., \& Chmil, J. V. (2014). Interprofessional education among student health professionals using human patient simulation. American Journal of Pharmaceutical Education, 78(5), 1-9. https://doi.org/10.5688/ajpe78594 
Bolger, J. (2014). Video self-modelling and its impact on the development of communication skills within social work education. Journal of Social Work, 14(2), 196-212. https://doi.org/10.1177/1468017313476982

Campinha-Bacote, J. (1998). The process of cultural competence in the delivery of healthcare services: A culturally competent model of care (3rd ed.). Transcultural C.A.R.E. Associates.

Campinha-Bacote, J. (2002). The process of cultural competence in the delivery of healthcare services: A model of care. Journal of Transcultural Nursing, 13(3), 181-184. https://doi.org/10.1177/10459602013003003

Campinha-Bacote, J. (2009). A culturally competent model of care for African Americans. Urologic Nursing, 29(1), 49-54.

Chadiha, L. A., \& Brown, G. W. (2002). Contributing factors to African American women caregivers' mental well-being. African American Research Perspectives, 8(1), 72-83. https://hdl.handle.net/2027/mdp.39015051717604

Congress, E. P., Black, P. N., \& Strom-Gottfried, K. (2009). Teaching social work values and ethics: A curriculum resource (2nd ed.). Council on Social Work Education.

Council on Social Work Education. (2008). 2008 Educational policy and accreditation standards. Author. https://www.cswe.org/getattachment/Accreditation/Standards-and-Policies/2008EPAS/2008EDUCATIONALPOLICYANDACCREDITATIONSTANDARDS(EPAS)-08-242012.pdf.aspx

Council on Social Work Education. (2015). 2015 Educational policy and accreditation standards. Author. https://www.cswe.org/getattachment/Accreditation/Standards-and-Policies/2015EPAS/2015EPASandGlossary.pdf.aspx

Cramer, E. P., Ryosho, N., \& Nguyen, P. V. (2012). Using experiential exercises to teach about diversity, oppression, and social justice. Journal of Teaching in Social Work, 32(1), 1-13. https://doi.org/10.1080/08841233.2012.637463

Cross, T. (1988). Services to minority populations: Cultural competence continuum. Focal Point, 3(1), 1-4. https://pathwaysrtc.pdx.edu/pdf/fpF88.pdf

Cross, T., Bazron, B., Dennis, K., \& Issacs, M. (1989). Towards a culturally competent system of care (Vol. 1). Georgetown University Child Development Center.

Davis, P., \& Donald, B. (1997). Multicultural counseling competencies: Assessment, evaluation, education and training, and supervision. Sage.

Davis, T. S. (2009). Diversity practice in social work: Examining theory in practice. Journal of Ethnic \& Cultural Diversity in Social Work, 18(1/2), 40-69. https://doi.org/10.1080/15313200902874961

Dempsey, M., Halton, C., \& Murphy, M. (2001). Reflective learning in social work education: Scaffolding the process. Social Work Education, 20(6), 631-641. https://doi.org/10.1080/02615470120089825

Duffy, J., Das, C., \& Davidson, G. (2013). Service user and carer involvement in role-plays to assess readiness for practice. Social Work Education, 32(1), 39-54. https://doi.org/10.1080/02615479.2011.639066

Ericsson, K. A. (2008). Deliberate practice and acquisition of expert performance: A general overview. Academic Emergency Medicine, 15, 988-994. https://doi.org/10.1111/j.1553-2712.2008.00227.x

Fong, R. (Ed.). (2004). Culturally competent practice with immigrant and refugee children and families. Guilford Press. 
Fong, R., \& Furuto, S. M. (Eds.). (2001). Culturally competent practice: Skills, interventions, and evaluations. Allyn \& Bacon.

Fowler, S. M., \& Pusch, M. D. (2010). Intercultural simulation games: A review (of the United States and beyond). Simulation \& Gaming, 41(1), 94-115. https://doi.org/10.1177/1046878109352204

Friedman, F. B., \& Goldbaum, C. S. (2016). Experiential learning: Developing insights about working with older adults. Clinical Social Work Journal, 44(2), 186-197. https://doi.org/10.1007/s10615-0160.583-4

Gaba, D. M. (2007). The future vision of simulation in healthcare. Simulation in Healthcare, 2, 126-134. https://doi.org/10.1097/01.SIHoo00258411.38212.32

Gallegos, J. (1982). The ethnic competence model for social work education. In B. W. White (Ed.), Color in $a$ White society (pp 1-9). National Association of Social Workers.

Gallegos, J. S., Tindall, C., \& Gallegos, S. A. (2008). The need for advancement in the conceptualization of cultural competence. Advances in Social Work, 9(1), 51-62. https://doi.org/10.18060/214

Gardner, F. (2001). Social work students and self-awareness: How does it happen? Reflective Practice, 2, 2740. https://doi.org/10.1080/14623940120035505

Green, J. (1995). Cultural awareness in the human services: A multi-ethnic approach. Allyn and Bacon.

Hanberg, A. D. (2008). The diffusion of high fidelity simulation in nursing education: Barriers and recommendations for best practice. (Doctoral dissertation). ProQuest. (304540028)

Hargreaves, R., \& Hadlow, J. (1997). Role-play in social work education: Process and framework for a constructive and focused approach. Social Work Education, 16(3), 61-73. https://doi.org/10.1080/02615479711220241

Hawala-Druy, S., \& Hill, M. (2012). Interdisciplinary: Cultural competency and culturally congruent education for millennials in health professions. Nurse Education Today, 32(7), 772-778. https://doi.org/10.1016/j.nedt.2012.05.002

Hayward, L., \& Li, L. (2014). Promoting and assessing cultural competence, professional identity, and advocacy in doctor of physical therapy (DPT) degree students within a community of practice. Journal of Physical Therapy Education, 28(1), 23-36. https://doi.org/10.1097/00001416201410000-00005

Hitchcock, L. I. (2017). Learning social work skills from simulations. https://www.socialworktoday.com/news/enews $0917 \quad 1 . s h t m l$

Johnson, B., \& Rawlings, M. (2011, October). Reliability and validity of the OSCE for social work practice performance rating scale. Paper presented at the Annual Program Meeting of the Council on Social Work Education, Atlanta, GA.

Johnson, C. H., Vicary, J. R., Heist, C. L., \& Corneal D. A. (2001). Moderate alcohol and tobacco use during pregnancy and child behavior outcomes. The Journal of Primary Prevention, 21(3), 367-378. https://doi.org/10.1023/A:1007025809914

Jones, A., \& Hegge, M. (2008). Simulation and faculty time investment. ClinicalSimulation in Nursing, 4, e5e9. https://doi.org/10.1016/j.ecns.2008.06.003

Klonoff, E. A., Landrine, H., \& Ullman, J. B. (1999). Racial discrimination and psychiatric symptoms among blacks. Cultural Diversity \& Ethnic Minority Psychology, 5(4), 329-339.

https://doi.org/10.1037/1099-9809.5.4.329 
Kurtz, S., Draper, J., \& Silverman, J. (2017). Teaching and learning communication skills in medicine. CRC press.

Lane, C., \& Rollnick, S. (2007). The use of simulated patients and role-play in communication skills training: A review of the literature to August 2005. Patient Education and Counseling, 67(1-2), 13-20. https://doi.org/10.1016/j.pec.2007.02.011

Latting, J. K. (1990). Identifying the "isms": Enabling social work students to confront their biases. Journal of Social Work Education, 26(1), 36-44. https://doi.org/10.1080/10437797.1990.10672132

LeGeros, M., \& Borne, J. S. (2012). Building bridges: Training social work students in domestic violence work. Field Educator, 2(2), 1-16. http://fieldeducator.simmons.edu/article/building-bridges-trainingsocial-work-students-in-domestic-violence-work/

Leventhal, T., \& Brooks-Gunn, J. (2003). Moving to opportunity: An experimental study of neighborhood effects on mental health. American Journal of Public Health, 93(9), 1576-1582. https://doi.org/10.2105/ajph.93.9.1576

Liaison Committee on Medical Education. (2012). Functions and structure of a medical school: Standards for accreditation of medical education programs leading to the MD degree. Author.

Logie, C., Bogo, M., Regehr, C., \& Regehr, G. (2013). A critical appraisal of the use of standardized client simulations in social work education. Journal of Social Work Education, 49(1), 66-80. https://doi.org/10.1080/10437797.2013.755377

Lu, Y. E., Ain, E., Chamorro, C., Chang, C., Feng, J. Y., Fong, R., Garica, B., Hawkins, R. L., \& Yu, M. (2011). A new methodology for assessing social work practice: The adaptation of the objective structured clinical evaluation (SW-OSCE). Social Work Education, 30, 170-185. https://doi.org/10.1080/02615479.2011.540385

Lum, D. (Ed.). (2005). Cultural competence, practice stages, and client systems. Thomson Brooks/Cole.

Lum, D. (Ed.). (2011). Culturally competent practice: A framework for understanding diverse groups and justice issues (4th ed.). Brooks/Cole.

Macgowan, M. J., \& Vakhanria, S. P. (2012). Teaching standards-based group work competencies to social work students: An empirical examination. Research on Social Work Practice, 22(4), 380-388. https://doi.org/10.1177.1049731512442249

McPhatter, A. R. (1997). Cultural competence in child welfare: What is it? How do we achieve it? What happens without it? Child Welfare, 76(1), 225-278. https://doi.org/o0o9-4021/97/010253-24

Mechanic, D. (2005). Policy challenges in addressing racial disparities and improving population health. Health Affairs, 24(2), 335-338. https://doi.org/10.1377/hlthaff.24.2.335

Miller, M. (2004). Implementing standardized client education in a combined BSW and MSW program. Journal of Social Work Education, 4O, 87-102. https://doi.org/10.1080/10437797.2004.10778481

Mooradian, J. K. (2007). Simulated family therapy interviews in clinical social work education. Journal of Teaching in Social Work, 27(1-2), 89-104. https://doi.org/10.1300/Jo67v27no1_06

Mooradian, J. K. (2008). Using simulated sessions to enhance clinical social work education. Journal of Social Work Education, 44(3), 21-35. https://doi.org/10.5175/JSWE.2008.200700026

Moss, B. (2000). The use of large-group role-play techniques in social work education. Social Work Education, 19(5), 471-483. https://doi.org/10.1080/026154700435995 
Motola, I., Devine, L. A., Chung, H. S., Sullivan, J. E., \& Issenberg, S. B. (2013). Simulation in healthcare education: A best evidence practical guide: AMEE Guide No. 82. Medical Teacher, 35(10), e1511e1530. https://doi.org/10.3109/0142159x.2013.818632

Nagda, B. A., Spearmon, M. L., Holley, L. C., Harding, S., Balassone, M. L., Moise-Swanson, D., \& Mello, S. D. (1999). Intergroup dialogues: An innovative approach to teaching about diversity and justice in social work programs. Journal of Social Work Education, 35(3), 433-449. https://doi.org/10.1080/10437797.1999.10778980

National Association of Social Workers (NASW). (2015). Standards and indicators for cultural competence in social work practice.

http://www.socialserviceworkforce.org/system/files/resource/files/Standards\%20and\%20Indicators \%20for\%20Cultural\%20Competence\%20in\%20Social\%20Work\%20Practice.pdf

National Association of Social Workers (NASW). (2017). Code of ethics. https://www.socialworkers.org/About/Ethics/Code-of-Ethics/Code-of-Ethics-English

Nimmagadda, J., \& Murphy, J. I. (2014). Using simulations to enhance interprofessional competencies for social work and nursing students. Social Work Education, 33(4), 539-548. https://doi.org/10.1080/02615479.2013.877128

Olson, M. D., Lewis, M., Rappe, P., \& Hartley, S. (2015). Innovations in social work training: A pilot study of interprofessional collaboration using standardized clients. International Journal of Teaching and Learning in Higher Education, 27(1), 14-24. https://files.eric.ed.gov/fulltext/EJ1069787.pdf

Pedersen, P., \& Marsell, A. (1982). The ethical crisis for cross cultural counseling and therapy. Professional Psychology, 13(4), 492-500. https://doi.org/10.1037/0735-7028.13.4.492

Petracchi, H. E., \& Collins, K. S. (2006). Utilizing actors to simulate clients in social work student role plays: Does this approach have a place in social work education? Journal of Teaching in Social Work, 26(12), 223-233. https://doi.org/10.1300/Jo67v26no1 13

Petrovich, A. (2004). Using self-efficacy theory in social work teaching. Journal of Social Work Education, 4O(3), 429-443. https://doi.org/10.1080/10437797.2004.10672298

Pew Research Center. (2015). Modern immigration wave brings 59 million to U.S., diving population growth and change through 2065. https://www.pewresearch.org/hispanic/2015/09/28/appendix-cpopulation-tables-19652065/

Potter, N., \& Allen, M. (2013). Clinical swallow exam for dysphagia: A speech pathology and nursing simulation experience. Clinical Simulation in Nursing, 9(10), E461-E464. https://doi.org/10.1016/j.ecns.2012.08.001

Reid, W. J., \& Hanrahan, P. (1982). Recent evaluations of social work: Grounds for optimism. Social Work, 27(4), 328-340. https://doi.org/10.1093/sw/27.4.328

Richardson, T. Q., \& Molinaro, K. L. (1996). White counselor self-awareness: A prerequisite for developing multicultural competence. Journal of Counseling \& Development, 74(3), 238-242. https://doi.org/10.1002/j.1556-6676.1996.tb01859.x

Rogers, A., \& Welch, B. (2009). Using standardized clients in the classroom: An evaluation of a training module to teach active listening skills to social work students. Journal of Teaching in Social Work, 29(2), 153-168. https://doi.org/10.1080/08841230802238203 
Saleh, M., Angela-Cole L., \& Boateng, A. (2011). Effectiveness of diversity infusion modules on students' attitudes, behavior, and knowledge. Journal of Ethnic and Cultural Diversity in Social Work, 2O(3), 240-257. https://doi.org/10.1080/15313204.2011.594995

Satcher, D., Fryer, G. E., McCann, J., Troutman, A., Woolf, S. H., \& Rust, G. (2005). What if we were equal? A comparison of the black-white mortality gap in 1960 and 2000. Health Affairs, 24(2), 459-464. https://doi.org/10.1377/hlthaff.24.2.459

Sue, D. W. (2001). Multidimensional facets of cultural competence. The Counseling Psychologist, 29(6), 790821. https://doi.org/10.1177/0011000001296002

Sue, D. W., Bernier, J. B., Durran, M., Feinberg, L., Pedersen, P., Smith, E., \& Vasquez-Nuttall, E. (1982). Position paper: Cross-cultural counseling competencies. The Counseling Psychologist, 1O(2), 45-52. https://doi.org/10.1177/0011000082102008

Suh, E. E. (2004). The model of cultural competence through an evolutionary concept analysis. Journal of Transcultural Nursing, 15(2), 93-102. https://doi.org/10.1177/1043659603262488

Sunarich, N., \& Rowan, S. (2017). Social work simulation education in the field. Field Educator, 7(1), 1-9. http://www2.simmons.edu/ssw/fe/i/16-130.pdf

Tervalon, M., \& Murray-Garcia, J. (1998). Cultural humility versus cultural competence: A critical distinction in defining physician training outcomes in multicultural education. Journal of Health Care for the Poor and Underserved, 9(2), 117-125. https://doi.org/10.1353/hpu.2010.0233

Thompson, B. M., Bratzler, D. W., Fisher, M. J., Torres, A., Faculty, E., \& Sparks, R. A. (2016). Working together: Using a unique approach to evaluate an interactive and clinic-based longitudinal interprofessional education experience with 13 professions. Journal of Interprofessional Care, $30(6)$, 754-761. https://doi.org/10.1080/13561820.2016.1227962

Vera, E. M., \& Speight, S. L. (2003). Multicultural competence, social justice, and counseling psychology: Expanding our roles. The Counseling Psychologist, 31(3), 253-272. https://doi.org/10.1177/0011000003031003001

Vesely, C. K., Ewaida, M., \& Anderson, E. A. (2014). Cultural competence of parenting education programs used by Latino families: A review. Hispanic Journal of Behavioral Sciences, 36(1), 27-47. https://doi.org/10.1177/0739986313510694

Villadsen, A., Allain, L., Bell, L., \& Hingley-Jones, H. (2012). The use of roleplay and drama in interprofessional education: An evaluation of a workshop with students of social work, midwifery, early years and medicine. Social Work Education, 31(1), 75-89. https://doi.org/10.1080/02615479.2010.547186

Weaver, H. N. (2005). Explorations in cultural competence: Journeys to the four directions. Thomson Brook/Cole.

Williams, D. R., \& Jackson, P. B. (2005). Social sources of racial disparities in health. Health Affairs, 24(2), 325-334. https://doi.org/10.1377/hlthaff.24.2.325

Wilson, A. B., Brown, S., Wood, Z. B., \& Farkas, K. J. (2013). Teaching direct practice skills using web-based simulations: Home visiting in the virtual world. Journal of Teaching in Social Work, 33(4-5), 421437. https://doi.org/10.1080/08841233.2013.833578

Winkelman, M. (2005). Cultural awareness, sensitivity, and competence. Eddie Bowers Publishing.

World Population Review. (2019). United States population. http://worldpopulationreview.com/countries/united-states/ 
Zubrzycki, J., Green, S., Jones, V., Stratton, K., Young, S., \& Bessarab, D. (2014). Getting it right: Creating partnerships for change. Integrating Aboriginal and Torres Strait Islander knowledges in Australian social work education and practice. Australian Government Office for Learning and Teaching.

http://www.acu.edu.au/ data/assets/pdf file/o010/655804/Getting It Right June 2014pdf

The Journal of Social Work in the Global Community, sponsored by the College of Social and Behavioral Sciences at Walden University, is a peer-reviewed journal and recognizes that social work is a global phenomenon with a myriad of contributors and perspectives. The journal is open to social work practice and research both domestically and abroad. 